\title{
LA CABALLERÍA MACEDONIA: TEORÍA Y PRÁCTICA
}

\author{
POR \\ JORGE JUAN MORENO HERNANDEZ
}

\begin{abstract}
RESUMEN - ABSTRACT
La eclosión de Macedonia en el siglo IV es paralela al desarrollo del ejército macedonio de Filipo. En ello la caballería jugó un papel decisivo, convirtiéndose por primera vez en la historia en el arma ofensiva por excelencia. Su aparición forma parte de una tendencia evolutiva, en la que Filipo será el mejor exponente. Sin embargo, la imagen de esta caballería no ha sido del todo entendida por buena parte de la historiografía. Por tanto, analizaremos la figura y evolución de la caballería griega en general, y la macedonia en particular: su composición, armamento, organización, y especialmente su despliegue y modo de combatir en batalla.

The emergence of Macedonia in the Fourth century b.C. is parallel to the rising of Philip's Macedonian army. In that army, cavalry played a decisive rol, becoming the offensive weapon par excellence. Its appearance is part of the evolution of that period's trends, where Philip played an important role. Nonetheless, cavalry's image has not been completely understood by contemporary historiography. Therefore, we will analize the evolution of Greek cavalry, and particularly Macedonian cavalry, in order to make it clear: its composition, equipment, organization, and specially its deployment and way of combat.
\end{abstract}

\section{PALABRAS CLAVE - KEY WORDS}

Caballería, Hippeis, Hetairoi, Siglo IV, Macedonia, Filipo de Macedonia, Alejandro Magno, Sarisa.

Cavalry, Hippeis, Hetairoi, Fourth Century, Macedonia, Philip of Macedon, Alexander the Great, Sarissa.

\section{INTRODUCCIÓN: LA CABALLERÍA GRIEGA EN EL SIGLO IV}

Durante largo tiempo se ha venido considerando a la caballería griega como un elemento secundario en el campo de batalla. Los hoplitas, la infantería pesada griega, fueron los dueños indiscutibles de la batalla durante este periodo: desde Maratón, Termópilas y Platea, hasta Leuctra y Mantinea, pasando por Cunaxa, Nemea, Coronea... Un sinfín de enfrentamientos en los que la caballería jugó un papel bastante secundario, frente a la brillante figura de la falange y el hoplita. La excesiva preocupación por este tipo de infantería ha llevado al deficiente entendimiento del papel desarrollado por la caballería, y buena parte de la historiografía contemporánea tiende aún hoy día a minusvalorar su labor durante este periodo ${ }^{1}$.

1 Tarn, 1930, 62; Adcock, 1957: 14; Brereton, 1976; G. Cawkwell, 1978: 151-152; de Ste. Croix, 1972: 372; Gaughan, 1990; Lazenby, 1989: 71; Pritchett, 1971, 132f. Hemos de constatar, no obstante, que la lectura de las fuentes confiere a la caballería un rol escaso o directamente ignorado, centrándose en los choques de las líneas de falange. Sin embargo, tanto la infantería ligera como la caballería irán adquiriendo un papel cada vez más importante en la escena militar griega, en especial a medida que termina el siglo V y entramos en el IV: ejemplo de ello son los enfrentamientos 
En cualquier caso, es evidente que la caballería griega es poco numerosa, y tiene una importancia menor en la guerra griega con anterioridad a la segunda mitad del siglo $\mathrm{V}$ a.C. Tanto es así, que sólo adquieren un papel destacado en las fuentes durante las Guerras Médicas (tanto la caballería persa como la beocia), en enfrentamientos como el de la caballería tesalia aliada de Hipias frente a los lacedemonios en 510, y en escaramuzas importantes durante la Guerra del Peloponeso (en Delio 424, en el Ática o en Siracusa, especialmente); prácticamente no volvemos a escuchar nada sobre ningún hecho significativo por parte de la caballería hasta la hegemonía tebana, con Leuctra o Mantinea. No es de extrañar por tanto que fuentes e historiografía contemporánea traten a la caballería como un elemento secundario (algo en cierto modo comprensible, ya que los griegos no utilizaron la caballería de forma extensiva).

Las causas de todo ello resultan evidentes: en primer lugar, la geografía griega es poco apropiada tanto para la cría de caballos como para su empleo y, del mismo modo, el mantenimiento de los caballos era una labor costosa desde el punto de vista económico y por tanto reservada a las clases pudientes ${ }^{2}$; segundo, el tipo de guerra hoplítica tradicional tiende a excluir al resto de las unidades de la batalla, dependiendo la resolución del combate del choque entre las falanges enemigas; tercero, el hecho de que en estos momentos los caballos no dispusieran de herraduras, ni los jinetes de silla de montar o estribos, hacía de la monta una actividad más complicada de lo que es hoy, y requería un duro entrenamiento, como veremos más adelante ${ }^{3}$.

Durante el periodo arcaico la caballería se había convertido en un elemento demasiado costoso e ineficiente como para utilizarlo de forma extensiva, en especial en lo que se refiere a sus posibilidades frente a la falange compacta de los hoplitas. Aparentemente se trata de un cuerpo efectivo, ya que retuvo algunas funciones notables como la exploración y el reconocimiento del terreno, su uso como pantalla, hostigadores o perseguidores; sin embargo, las fuentes demuestran que tales funciones pertenecen más a la teoría que a la práctica, ya que pocas veces se utilizaban exploradores en las campañas griegas, muchas menos como pantalla, y no se usaba de forma extensiva como para suponer una verdadera amenaza utilizando su potencial de fuego. Parece que la caballería va ganando en importancia durante la Pentecontecia y especialmente durante la Guerra del Peloponeso ${ }^{4}$ : en ella, la caballería tendrá una magnífica oportunidad para demostrar su valía, tanto para contrarrestar incursiones e invasiones, como para llevarlas a cabo (con el caso paradigmático de Atenas); previene ataques contra el flanco y destruye a las fuerzas que huyen; en la batalla de Delio (424) tuvo un peso decisivo al atacar al enemigo por la espalda, en Mantinea (418) la caballería ateniense evita el envolvimiento de su flanco izquierdo y la aniquilación de su ejército, y en Sicilia, los atenienses son derrotados en buena parte gracias a la superioridad manifiesta de la caballería siracusana (amén de la infantería ligera).

de Esfacteria (425), Delio (424), Sardes (395), Corinto (390), Leuctra (371) y Mantinea (362), entre otros. Ello no significará en absoluto el desplazamiento de la infantería pesada.

2 A excepción de las llanuras de Tesalia y Beocia, la Grecia continental apenas contaba con zonas de agua y pastos suficientes para el natural mantenimiento de caballos, en especial en los meses de verano (época de campañas). Ello contrasta con la situación de las colonias griegas en el Este y el Oeste, tal y como aparece en el registro arqueológico. Véase al respecto Anderson, 1961; Sekunda, 1992; Snodgrass, 1967; Spence, 1993.

3 Los jinetes se sujetaban a sus monturas ejerciendo una fuerte presión con sus piernas contra los costados del caballo, lo que suponía un gran esfuerzo además de las limitaciones en la conducción y el control de la montura.

4 Su número es indicativo al respecto: la caballería ateniense pasa de 96 a 300 jinetes hacia el $460-457$ a.C., y a 1.000 entre 445 y 438; la caballería beocia, tras recuperar la independencia perdida frente a Atenas en 446, dispone de un cuerpo de 1.100 jinetes hasta 387, cifra que retomará tras la recuperación de su independencia y su confederación, en la década siguiente; la caballería tesalia, la más destacada dentro de la Grecia Continental, fue capaz de enviar 1.000 jinetes a Hipías en 510; bajo Jasón de Feras, Tagos de la Liga Tesalia, el cuerpo de caballería cuenta con 6.000 efectivos (incluido un alto número de mercenarios) y 2.000 aliados; posteriormente en el s. IV son unos 2.000; Esparta, por su parte, no formará un cuerpo de caballería hasta 425/24, como respuesta a los ataques costeros atenienses, cuerpo que constará de 400 jinetes. Véase Spence, 1993; Worley, 1994; Anderson, 1961. 
Dentro de la caballería de origen griego destacan las de regiones como Tesalia y Beocia ${ }^{5}$, más aptas para la cría desde el punto de vista geográfico. Ambas dispondrán a sus jinetes en formación durante el siglo IV, una formación que podía ser empleada con garantías contra la caballería o la infantería ligera enemigas ${ }^{6}$. Tracia y Macedonia también dispusieron de unidades de caballería de importancia, y al igual que tesalios y beocios, también desplegaron a su caballería en formación, concretamente en cuña, por influencia de los jinetes escitas del norte ${ }^{7}$. Será sin embargo con Filipo y Alejandro cuando esta caballería adquiera un papel fundamental en la batalla, tan importante como el de la propia infantería pesada.

No existía un equipamiento estándar entre los jinetes griegos, y dependía de las preferencias del individuo o de una región concreta. El armamento defensivo habitual consistía básicamente en casco, coraza o peto (normalmente), y botas altas, ya que la tendencia en la caballería es inversa a la hoplítica, esto es, aumenta la protección de los jinetes y con ello su seguridad, sin que suponga una merma significativa en su movilidad (cuentan además con medios económicos suficientes). El armamento ofensivo estaba formado por dos jabalinas o una lanza (en ocasiones por ambas), y quizá espada, de acuerdo con las preferencias del jinete y su procedencia regional ${ }^{8}$.

La caballería era habitualmente situada en las alas de la infantería pesada de línea para defender y amenazar el flanco y la retaguardia enemigas durante la batalla ${ }^{9}$ Solía dar comienzo a la misma hostigando junto a la infantería ligera a la falange enemiga (tratando de hacerles perder la formación), o atacando directamente a la caballería y los ligeros enemigos. Su uso era especialmente adecuado en la conclusión de la batalla, durante la persecución del enemigo o la protección de la huida de la infantería propia ${ }^{10}$. Fuera de la batalla, la caballería era particularmente efectiva frente a infantería que hubiera perdido la formación, saqueadores, forrajeadores, infantes ligeros... ${ }^{11}$.

A finales del siglo $\mathrm{V}$ y sobre todo durante el IV la situación va a experimentar un cambio importante, y la caballería, junto a la infantería ligera, pasaron a adoptar un papel decisivo en combinación con la infantería hoplítica ${ }^{12}$. Se tiende a pensar que las batallas de Leuctra y

5 Tuc. 2.9, 3.62, 5.95, Jen. Hel. 6.4.10, 7.5.16.

6 Epaminondas fue el primero en desplegar a su caballería en triángulo en Mantinea (362). También sabemos que la caballería tesalia combatía en rombo, si bien no está tan clara la finalidad de dicha formación: quizá así pudiera girar 90 y 180 grados sin variar la formación, o al concentrar mayor profundidad en su centro tuviera una mayor capacidad de penetración en la formación enemiga.

7 Asclepiódoto Tact. 7.3, Eliano Tact. 18.4

8 La caballería tesalia, por ejemplo, portaba cascos de tipo petasos contra el calor y el polvo, y una capa que los

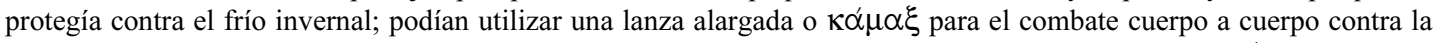
infantería o la caballería enemigas. La ateniense, por su parte, vestía túnicas sin mangas llamadas $\chi \imath \tau \omega v i ́ \sigma \kappa o \zeta$, y sobre ellas corazas anatómicas unidas por dos bandas estrechas sobre los hombros y más abiertas en el abdomen, lo que permitía al jinete gozar de mayor movilidad; los atenienses toman el armamento tesalio con $\kappa \alpha ́ \mu \alpha \xi$ y petasos (que sustituirán por cascos de tipo beocio a mediados del IV), pero era igualmente habitual verlos armados con sable y un par de jabalinas, que era el armamento más común entre la caballería. Es poco probable que los jinetes vistieran de manera uniforme o utilizaran los mismos colores en sus ropajes. La caballería lacedemonia también está armada con lanza y casco del tipo pilos, y su vestimenta es más irregular. En cualquier caso, la caballería de esta época tendía a equiparse con jabalinas para el combate a distancia, lo cual se veía favorecido por su movilidad. De acuerdo con Snodgrass, 1967, 119-121, en este periodo aumentaron las protecciones de la caballería griega. Véase también: Sekunda 1992; Anderson, 1961; Ducrey, 1986; Hutchinson, 2000; Spence, 1993; Worley, 1994.

9 Tuc. 4.93.4-94.1, Asclepiódoto Tácticas 7.

10 Platón, Simposio 220E7-221C1.

11 Hdt. 9.69.1-2, Jen Hel. 7.1.20-21.

12 No en vano el número de infantería ligera y caballería va en aumento en este periodo, de la mano de la inclusión de los peltastas en la escena griega, y la sabia combinación de todos estos tipos de tropas suponía invariablemente la superioridad de un ejército sobre otro. El propio Jenofonte habla de la combinación entre infantería ligera y caballería, Hip. 5.13: Jenofonte se está refiriendo a la infantería de los $\alpha ́ \mu \imath \pi \pi \circ \imath \pi \varepsilon \zeta o$, un tipo de soldado ligero especialmente entrenada para combatir junto a la caballería y que podía decantar la balanza en un enfrentamiento de caballería. Son 
Mantinea supusieron un cambio revolucionario respecto al periodo precedente por su formación oblicua, desplegada a la izquierda, por el uso de la caballería (en formación triangular) como unidad de choque, con el apoyo de infantería ligera, y con la falange (de cincuenta escudos de profundidad y el Batallón Sagrado al frente) por detrás preparada para caer sobre el enemigo utilizando el factor sorpresa y la velocidad ${ }^{13}$. Sin embargo, esta tendencia formaba parte de un largo proceso de evolución, tal y como leemos en la evolución de los enfrentamientos de este periodo, y en el que pone especial énfasis el profesor Hanson, quien lleva a cabo una relectura de las grandes victorias de Epaminondas ${ }^{14}$. No obstante, sí es cierto que Epaminondas llevó a cabo una perfecta adaptación de las nuevas tendencias en el uso de la caballería y la infantería ligera, así como una sabia relectura del papel de la falange, realizando un ataque combinado con todos ellos contra la línea enemiga, concentrando sus fuerzas en un punto escogido, cogiendo al enemigo por sorpresa y sacando provecho de su velocidad y su superioridad. Su caballería es desplegada en primera línea como pantalla para ocultar la concentración y preparación de la falange tebana ${ }^{15}$, ataca a la enemiga derrotándola, crea confusión y desmoralización en las líneas, amenaza los flancos y la espalda del enemigo, y crea las condiciones necesarias para el ataque hoplita.

De forma paralela, podemos encontrar otros ejemplos anteriores de coordinación entre caballería e infantería, como son las batallas de Delio en $423^{16}$, la de Cunaxa y la Anábasis de los Diez Mil de Jenofonte ${ }^{17}$, o las campañas de Agesilao en Asia Menor, en especial la batalla de Sardes de $395^{18}$. Por el contrario, la mala utilización de la caballería, anclada en

infantes ligeros pero bien equipados para su cometido, que corren tras los caballos, a veces agarrados a su cola o montando a la grupa del caballo, para desmontar antes del combate y luchar desde tierra al lado de sus jinetes. Eran especialmente hábiles en la lucha contra caballería enemiga, desmontando a los jinetes de sus caballos, o matando a los caballos enemigos. Los hamippoi más conocidos son los beocios, que dieron a la caballería beocia la superioridad sobre la ateniense y la lacedemonia durante el periodo de la hegemonía (Diod.15.85.4. Jen. Hel. 6.4.10, Equit. 12.3). No obstante, los primeros hamippoi de que tenemos constancia son los de Gelón de Siracusa (Heródoto 7.158), posteriormente los beocios durante la Guerra del Peloponeso, y los seiscientos esciritas lacedemonios del 418.

13 J. Buckler, 1980: 266 y 320; Westlake, 1975: 23-40; Anderson, 1970: 199; Adcock, 1957: 89; Cawkwell, 1972: 262; Ducrey, 1986, 79-80; Hutchinson, 2000: 101-110; Worley, 1994, 141-151. Para la mayoría de ellos el papel de la caballería aumenta bajo la hegemonía tebana: actúan como pantalla, defienden los flancos y la retaguardia, actúan en labores de reconocimiento y exploración, pillajes y saqueos... pero también en el ataque sobre los flancos, y podrían incluso aprovechar los huecos surgidos en el enemigo. Así en Mantinea Epaminondas manda a su caballería en forma-

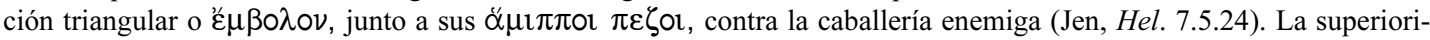
dad de la caballería tebana quedará patente merced a su formación de combate, a sus hamippoi y a su mayor experiencia y entrenamiento. En conjunto, se tiende a pensar que Mantinea fue la primera batalla en la cual la caballería griega fue utilizada como tropa de choque.

14 Hanson, 1988: 190-207. También Worley, 1994, 151: «Epaminondas' use of his cavalry was the culmination of a half century of attention and development».

15 Para Hanson, 1988: 195-196, tanto espartanos como tebanos situaron su caballería delante de sus líneas, y tras el combate entre ambas, la lacedemonia se lanza sobre sus propias filas en la huida; y Jen. Hel. 6.4.10-13 dice claramente que fueron los espartanos los que primero eligieron esta posición, y que el desastre fue debido a la inexperiencia de la caballería espartana. Tampoco explica que la caballería creara un hueco que no pudieron tapar los espartanos. Por tanto, lo considera más una reacción acertada que un movimiento previo y deliberado tebano.

16 Tuc. IV.96. La caballería beocia rodea al ejército ateniense y carga contra su espalda, causando terror entre sus enemigos, que además creían que se acerca un nuevo ejército.

17 Jenofonte cuenta cómo han de crear cuerpos de caballería y honderos, que en conjunción con sus arqueros (que toman arcos persas, de mayor alcance), mantienen a raya al enemigo junto a los antes indefensos hoplitas y peltastas. De hecho, la combinación de una carga de caballería, seguida de los ligeros y los hoplitas en masa, derrota y pone en fuga al ejército persa, que sufre serias bajas. Jen. Anab. 3.3.7-10, 3.4.3-5.

18 Jen. Hel. 3.4.23-24. Agesilao, combinando caballería, infantería ligera e infantería pesada, derrota a las fuerzas de caballería persa en Asia Menor. Rahe, 1980: 94-95, sostiene que la auténtica revolución militar se dio en Asia cuando Ciro y Agesilao intentaron emplear por vez primera unidades de caballería como parte integral del ataque hoplítico, si bien parece una tendencia demasiado exagerada, ya que se trató de un fenómeno aislado. Véase también Worley, 1994: 127-141. 
las tácticas del pasado, podía conducir al desastre, como ocurrió a los espartanos en 390 frente a Ifícrates, en las cercanías del Lequeo ${ }^{19}$.

\section{LA CABALLERÍA MACEDONIA}

Pese al desarrollo militar griego de este periodo, el verdadero salto cualitativo y cuantitativo no se producirá hasta la llegada de Filipo de Macedonia y su hijo Alejandro. Con ellos el antiguo ejército macedonio, compuesto por la caballería aristocrática tradicional y la infantería ligera de baja calidad, se transforma en aquel fruto de las reformas de Filipo, que se impondrá en Grecia y los Balcanes durante su reinado, y en todo el Imperio Persa durante el reinado de Alejandro.

Hasta entonces, la caballería había sido siempre la base del ejército macedonio, compuesta por la aristocracia territorial que detentaba el poder con el monarca ${ }^{20}$, y junto a ella combatía la gran masa de infantería ligera deficiente y mal armada ${ }^{21}$. Esta caballería estaba equipada inicialmente de forma similar a la tesalia y la beocia, con cascos, armaduras, botas altas, $\kappa \alpha \dot{\alpha} \alpha \xi$ o jabalinas, y espada. Pese a la calidad de la misma, los monarcas macedonios anteriores a Filipo no pudieron evitar verse a merced de los ejércitos griegos, tracios o ilirios durante los setenta años anteriores a la subida al trono de éste.

\section{CARACTERÍSTICAS DE LA CABALLERÍA DE FILIPO}

Como sabemos, Filipo de Macedonia llevó a cabo una profunda reforma en el interior de su ejército que afectó a todos los cuerpos del mismo, entre ellos la caballería. Comencemos hablando de los efectivos de caballería: a comienzos de su reinado, éstos no superaban los seiscientos jinetes, como leemos en su primer gran enfrentamiento frente al ilirio Bardilis, en 35822; este número aumentará notablemente hasta cerca de tres mil jinetes entre macedonios y aliados, en la batalla de la Llanura del Azafrán de 353, y unos dos mil en Queronea, $338^{23}$. Si tenemos en cuenta las cifras que se nos ofrecen sobre Alejandro en 334, es muy posible que Filipo dispusiera de unos dos mil ochocientos compañeros y mil cuatrocientos jinetes de caballería ligera en los últimos años de su reinado ${ }^{24}$. Dicho aumento podemos atribuirlo a diversas causas: Filipo incorporó entre sus Hetairoi a la nobleza de la Alta Macedonia; asimismo, aceptó en sus filas a cierto número de extranjeros (especialmente griegos), a los que concedió algunas tierras en su reino; y tercero, el ligero aumento demográfico macedonio, favorecido por la coyuntura económica y la expansión territorial (si bien su incidencia es menor, y más a largo plazo). A ello habríamos de añadir aquellas unidades de caballería aliadas que combatirán con el ejército macedonio en la mayor parte de los enfrentamientos de Filipo y Alejandro, en especial la de los tesalios.

La superioridad de la caballería macedonia durante este periodo quedó de manifiesto en la mayoría de los enfrentamientos de que nos ha quedado constancia. Ya hemos tenido oca-

19 Jen. Hel. 4.5.13-18. Los peltastas de Ifícrates, con el apoyo de los hoplitas de Calias, derrotan a una mora espartana a la que de nada sirvió contar con el apoyo de su caballería, ya que perseguía al mismo ritmo que los ع̌ $\kappa \delta \rho \mu o \imath$ lacedemonios.

20 Diod. 16.4, Tuc. 2.100.6; Brun, 1963: 27ff; Griffith, 1979: 408ff; Borza, 1990: 202; Hammond, 1989: 104ff, Ellis, 1976: 687ff.

21 Tuc. $2.100 .5,4.125 .1$ y $126.3-5$.

22 Diod. 16.4.

23 Diod. $16.35 .4-5$ para el 352; 16.84 para el 338.

24 Diodoro 17.17, Arr. 1.11.3. 
sión de valorar una de las principales causas, el aumento de sus efectivos y la incorporación de la caballería tesalia en sus filas. Pero debemos considerar una serie de elementos paralelos de igual consideración:

En primer lugar, la formación, la disciplina y el entrenamiento que recibía esta caballería macedonia ${ }^{25}$. Ya desde su infancia los hijos de la aristocracia macedonia se ejercitaban en la monta; a la edad de catorce años entraban en el cuerpo de pajes del rey; y a los dieciocho, tras concluir este periodo de entrenamiento, pasan a formar parte de los guardaespaldas del rey; Finalmente se convertían en $\varepsilon \tau \alpha i ̂ p o l$, Compañeros del rey ${ }^{26}$. La efectividad de los ejércitos macedonios de Filipo y Alejandro se vio también favorecida por el aumento de la disciplina y el alto control de las tropas durante la acción ${ }^{27}$. Todo ello convertirá al ejército macedonio en un ejército profesional y cualificado.

De forma paralela, la coyuntura geográfica y económica era bastante favorable, dada la existencia de grandes llanuras y pastos para la cría de caballos. Al mismo tiempo, los grandes latifundios de los aristócratas macedonios les permitían mantener un buen número de animales. Igualmente, se cuenta que los caballos macedonios eran superiores al resto de los balcánicos, ya que durante el reinado de Alejandro I y la dominación persa se introdujeron caballos de Media, mejores aún que los del Danubio y el Norte, y se criaron en las llanuras de la Baja Macedonia.

En cuanto a su organización, los Compañeros estaban perfectamente divididos en ‘` $\lambda \alpha \mathbf{l}$

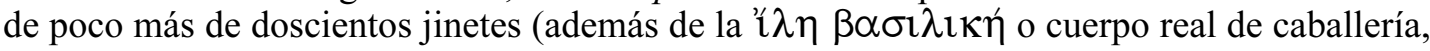
compuesto por los jinetes más selectos), al mando de un ilarca. Finalmente, la formación en cuña que adoptó la caballería macedonia en tiempos de Filipo y Alejandro nos hace pensar en una disposición agresiva y con capacidad de penetración en las filas enemigas ${ }^{28}$.

\section{ARMAMENTO DE LA CABALLERÍA MACEDONIA}

Ya hemos comentado que el armamento macedonio era en su mayor parte el mismo que aquel de que disponían los griegos ${ }^{29}$. Sin embargo, con la reforma militar de Filipo surge un nuevo tipo de lanza destinada a convertirse en el arma emblemática macedonia: la sarisa.

25 Pese a que las fuentes no dicen nada de forma directa, intuimos el alto grado de importancia que le concedía el macedonio a la disciplina en Frontino, Estratagemas 4.2.4, cuando dice que «los hombres estaban acostumbrados a la disciplina bajo Filipo», o las anécdotas en que el monarca prohibía y castigaba cualquier lujo entre sus tropas: Diod. 16.3, Polieno 4.2.10, Frontino 4.1.6.

26 Hammond, 1990: 261-289.

27 Sirva de ejemplo Curcio 3.2.13-14: «El ejército macedonio, torvo en verdad y tosco, esconde tras sus escudos y sus lanzas sus inamovibles formaciones en cuña y una fuerza compacta de guerreros. A tal formación le dan el nombre de falange, sólido cuerpo de infantería. Los soldados están entrelazados unos con otros, las armas con las armas; fija su atención en la señal del comandante, saben seguir a los estandartes y guardar la formación; todos ponen en práctica las órdenes recibidas. Hacer frente, acorralar al enemigo, hacerse a un lado, cambiar de frente, lo conocen tan bien los soldados como los jefes».

28 De acuerdo con Eliano Táctica 18.4, fue Filipo quien introdujo esta formación. La tomó de tracios y escitas, al ser más efectiva que el cuadro (Asclepiódoto Táctica 7.3). Asimismo, hay quien cree que los corceles de la caballería pesada pudieron equiparse con algún tipo de petos o testeros ligeros, lo que potenciaba su fuerza en el choque: un par de ejemplos de estos elementos los podemos contemplar en Connolly, 1981, p. 73, pl. 1-2.

29 Tal y como aparecen representados los Hetairoi en el Mosaico de Alejandro, en el Sarcófago de Alejandro y en el fresco de la Tumba de Naoussa, estos jinetes estaban equipados con cascos y corazas, sin la impedimenta de los escu-

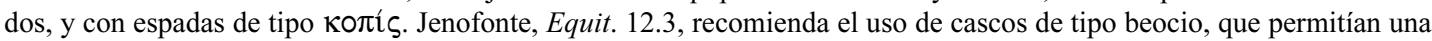
mejor visibilidad, si bien muchos de los macedonios debieron portar cascos de ala ancha del tipo tesalio o petasos. Griffith, 1979: 417, opina también que la caballería macedonia pudo estar equipada además con un escudo ligero, basándose en las descripciones de Gránico en Diod. 17.21.2, Plut. Ale. 16, y frente a representaciones que ya hemos mencionado; Bosworth, 1996: 383-384, lo acepta como una posibilidad. En cualquier caso, no es la tendencia general. 
Se ha escrito mucho sobre la lanza macedonia, y todavía hoy se debate en torno a detalles tales como su longitud y sus dimensiones, o la terminología utilizada ${ }^{30}$. En primer lugar, no queda del todo claro el hecho de que las sarisas de caballería fueran llamadas $\xi u ́ \sigma \tau o v$ y $\delta o ́ p v$ en las fuentes ${ }^{31}$. Parece además que su tamaño era menor que el de las sarisas de infantería, pero superior al resto de las armas (lo que potenciaba su carácter ofensivo) ${ }^{32}$. De acuerdo con Manti, es muy posible que las fuentes simplemente recogieran la presencia de esta lanza de caballería de grandes dimensiones con diferentes nombres, y que fuera el arma básica de los Sarisoforoi, así como de los Compañeros en determinadas ocasiones. La caballería macedonia, al igual que la griega, recibía instrucción en varios tipos de armas, y se equiparían con sarisas, lanzas o jabalinas de acuerdo con las circunstancias ${ }^{33}$.

La sarisa de caballería, también llamada kontos, o incluso $\kappa \alpha ́ \mu \alpha \xi$, es una lanza de no menos de ocho codos, si seguimos a Elio, lo que según Manti supondría cerca de tres metros (ya que lo traduce como codos macedonios), y no llega a los dos kilogramos de peso ${ }^{34}$. Posee un asta de madera de cornejo y dos puntas de hierro en ambos extremos, lo que sirve como contrapeso a la hora de sostener la lanza; al mismo tiempo, tiene un mayor rango de golpeo, ya que permitía asestar golpes a ambos lados, hacia delante y hacia atrás, sin realizar giros bruscos y con cierta comodidad (ya que de otra forma sería prácticamente imposible si tenemos en cuenta las dimensiones y el peso de la sarisa), sosteniéndola sobre el brazo para golpear a la infantería, de arriba abajo, y bajo el brazo para golpear en paralelo contra la caballería enemiga ${ }^{35}$; tenía también la opción de golpear hacia abajo con la segunda punta sin tener que cambiar la empuñadura de la lanza, lo que resulta útil para rematar a los enemigos. La punta trasera permitía también cambiar la empuñadura dándole la vuelta a la lanza. Y en el caso de que una de las puntas se rompiera (sobre todo la delantera), podían utilizar la restante y no verse abocados al uso de la espada. Sus tres metros de largo son además suficientes como para superar el alcance del enemigo y obtener con ello una ventaja decisiva. Pese al tamaño, su ligereza permitía un fácil manejo, sin que llegue a fatigar ${ }^{36}$.

Junto a la sarisa, estos jinetes portaban una tira de cuero que ataba la sarisa a la cintura por el asta, dada la posibilidad de perderla en combate o de que se rompiera. En caso de perder definitivamente la sarisa, quedan las espadas adicionales del tipo kopis o machaira, armas de tajo o corte más útiles en caballería que las de punta o punzada.

30 Sobre la sarisa de caballería: Markle, 1977: 323-29; Manti, 1983: 73-80; Griffith, 1979: 411-14; Hammond, 1989: 123-126; Andronikos, 1970: 91-107.

31 Encontramos el primer término en Arr. Anab. 1.15.5, y el segundo en 1.15.7-8.

32 En mi opinión, Manti, 1983, 73-80, resulta bastante convincente al establecer una diferencia clara entre la sarisa de caballería y la de infantería. Markle, por su parte, no establece diferencia alguna entre ambos tipos de sarisas, lo que es seguido de forma tácita por algunos especialistas: Hammond, 1980: 53-63; Connolly, 1981.

33 Como podemos leer en las campañas de Alejandro. Manti, 1983, 73-80. Este equipo aparece así representado en el Mosaico de Alejandro, en el Sarcófago de Alejandro y en el fresco de la Tumba de Naoussa.

34 Táctica 12; Manti, 1983, 73-80, el peso exacto es 1,9 Kg. . Si seguimos a quien sostiene que la sarisa de caballería apenas difería de la de infantería (Markle, 1977, 338), entonces la sarisa tendría entre cinco y siete metros de tamaño, o poco menos de cinco metros. Pese a las previsibles variaciones en cuanto al tamaño y al peso (ya que es lógico pensar que existió una clara diferenciación entre sarisa de infantería y de caballería, a la vista de las evidentes diferencias entre el combate a pie y a caballo), ambas son en esencia iguales, ya que los objetivos que se persiguen son los mismos.

35 Como veremos a continuación, el golpeo depende del brazo, no del empalamiento con la lanza en ristre (dependiente de masa y velocidad de caballo y jinete en la carga). De este modo, el golpeo de jinete contra otro jinete podía dirigirse contra la cabeza del caballo o contra el jinete, lo que hacía más probable desmontar al enemigo que matarlo. Véase Devine, 1989, 106-107; Quesada, 2003b, 106. Markle 1977, en cuatro imágenes, ofrece una idea bastante clara sobre la forma de sostenerla.

36 Worley, 1994: 156. Polibio comenta que esta sarisa podía ser incluso lanzada como si fuera una jabalina. En mi opinión, y pese a su ligereza y su tamaño menor que las sarisas de infantería, es una posibilidad difícil y totalmente excepcional, que únicamente pretende ejemplificar su ligereza. 


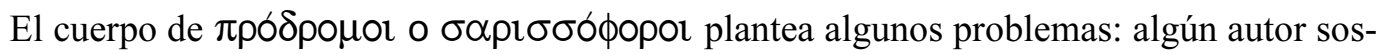
tiene que las sarisas que portan son de infantería, más largas que las habituales sarisas de caballería ${ }^{37}$; y es curioso también que una caballería ligera y de exploración estuviera equipada con un arma tan pesada. Ello la convierte además en una unidad de choque, con alcance muy superior al enemigo. No en vano fue utilizada como avanzadilla o punta de lanza en Gránico y en Isos, abriendo el ataque ${ }^{38}$. Su número era inferior al de los compañeros, formando únicamente cuatro ' $i \lambda \alpha l$, seiscientos jinetes. Sus funciones, según parece, eran las de reconocer el terreno, participar en las misiones que requerían de gran velocidad, apoyar a los Hetairoi $i$ e incluso actuar como caballería de asalto.

Existe un problema en cuanto a la formación adoptada por la caballería: ya hemos hablado del triángulo macedonio, pero una formación de tales características, formada por jinetes armados con lanzas que rondaban los tres metros o más, debía implicar una serie de problemas en cuanto a la disposición de los jinetes, si tenemos en cuenta que las lanzas de las filas posteriores estorbarían tanto a las delanteras como a las traseras. Si partimos de la posición de estas lanzas en las diversas fuentes ${ }^{39}$, podemos llegar a la conclusión de que estas sarisas eran sostenidas aproximadamente a cinco codos de la punta y tres del regatón (sobre una sarisa de ocho codos), de forma que su peso estuviera distribuido y su empleo fuese más cómodo. Teniendo ello en cuenta, podemos mantener que los jinetes armados con sarisas se alineaban en una formación ligeramente más abierta, con más distancia entre filas, y con las lanzas posteriores sobreelevadas, de forma que pudiera maniobrar con mayor facilidad ${ }^{40}$.

\section{LA CABALLERÍA EN COMBATE}

Resulta evidente que un arma como la sarisa limitaba las posibilidades de la caballería macedonia al combate cuerpo a cuerpo y a la carga, ya que se trata de un arma decididamente ofensiva y pesada. Una formación macedonia debía confiar en la mayor longitud de su lanza, especialmente efectiva frente a la caballería enemiga o a cualquier cuerpo de infantería ligera. En cuanto a la infantería pesada de línea existe cierta controversia:

El profesor Markle, partiendo de algunas de estas premisas, se muestra de acuerdo con la posibilidad de que la caballería macedonia pudiera efectuar cargas directas contra infantería pesada de línea, gracias en buena parte a la introducción de la sarisa de caballería y a la formación en cuña, que era utilizada por Filipo para penetrar las formaciones de hoplitas griegos $^{41}$. Resulta evidente que estas sarisas, en manos de Hetairoi o Sarissoforoi, daban a sus portadores una ventaja evidente, como era la de superar el alcance del enemigo. Markle destaca en su argumentación las imágenes del relieve de la Tumba de Payava, datada a comienzos del s. IV, en la que parece que unos caballeros están cargando contra una formación de infantería ${ }^{42}$. Los demás restos muestran únicamente combates heroicos en duelos o tríos, por

37 Worley, 1994: 156.

38 Arr. Anab. 1.14.6 para Gránico; Anab. 2.9.2, 2.10.3 para Isos.

39 Manti, 1983: 73-80, y Markle, 1977, 333-339 y figuras 1-4, explican detalladamente cómo podían transportar estos jinetes tales lanzas, así como su funcionalidad, basándose en el Mosaico de Alejandro, el Sarcófago de Alejandro, el Fresco de la Tumba de Naoussa o el Bajorrelieve de Apolonia en Epiro.

40 Bosworth, 1996: 384, sostiene sin embargo que una compañía de Sarissophoroi o Compañeros armados con sarisas no podía combatir en formación. Pese a que no lo compartimos, sí debemos reconocer que esta cuestión supondría una de las complicaciones para el despliegue de este tipo de caballería pesada.

41 Markle, 1977, 333-8; también Delbruck, 1975: 176; Devine, 1989: 105.

42 Dos jinetes se enfrentan a dos infantes armados con escudos ovalados: es posible que la caballería se encuentre en formación, contra unos infantes formados en dos filas; no obstante los jinetes están equipados con escudos, y el resto del armamento aparece de forma poco clara. 
lo que no nos sirven de ayuda ${ }^{43}$. El principal punto de apoyo en esta tesis han de ser las fuentes escritas, en especial Diodoro y Arriano ${ }^{44}$ : en ellos podríamos intuir que la caballería macedonia carga directamente contra formaciones aparentemente intactas, tal y como ocurre en Isos y quizá en Queronea ${ }^{45}$. Por todo ello, Markle llega a la conclusión de que Filipo armó a sus jinetes con sarisas para cargar contra los hoplitas.

No obstante, existen numerosas objeciones a la recién expuesta teoría. La primera de ellas es que los jinetes aún no conocen la silla de montar ni los estribos, con la inestabilidad que ello conlleva, y máxime en una carga de tales características ${ }^{46}$. Esta es la principal razón por la que la mayoría de los autores descartan tal opción ${ }^{47}$. El desconocimiento de los estribos, tan señalado por muchos, suponía indudablemente una merma en la estabilidad de la caballería, pero si dicho problema hubiera sido insalvable, no hubiera existido una caballería tan numerosa ni en Grecia ni en el mundo antiguo. Los griegos desarrollan una serie de prácticas que, aunque menos efectivas que los estribos (especialmente en cuanto a los problemas de mantenimiento y armamento) sí los alivian: práctica y entrenamiento constante, uso de bocados severos y de los animales más apacibles que inspirasen confianza, la educación de los mismos, las posturas de monta... todo ello destinado a minimizar la inestabilidad y mejorar el uso de las armas sobre el caballo ${ }^{48}$.

La segunda «objeción» que hemos de abordar es más importante si cabe que la primera: el comportamiento del propio caballo. A lo largo de la historia, el caballo es incapaz de cargar contra una formación de infantería estable y sólida. En estas circunstancias, las monturas simplemente se niegan a chocar contra una barrera o bloque de personas (que además se mueve y vocea), declinando el ataque o girando de forma que eviten el contacto o rodeen al enemigo ${ }^{49}$. Los caballos macedonios, por más que fuesen superiores a los griegos, no fueron una excepción.

La profesora Worley sostiene que, pese a que dicho razonamiento es cierto en buena parte, tiende a ignorar las condiciones especiales de una carga de caballería: en ella los caballos, lanzados al galope y al igual que en una estampida (controlada), chocarían con cualquier

43 Debemos recordar no obstante que entre las representaciones helénicas no encontramos apenas representaciones de combates entre formaciones. Tanto es así que las escenas de combates entre falanges griegas se reducen al vaso Chigi, y poco más. Por tanto, este tipo de restos no son en absoluto concluyentes.

44 Más aún este último, ya que era comandante romano de caballería, y por tanto una fuente teóricamente fiable en este aspecto.

45 Isos: Arr. 2.8.2-11.7, Polibio 12.5-22 (FGrH 124 F 35), Diod. 17.33-34, Plutarco Alejandro 20.8, Justino 11.9.9, Curcio 3.8-11; N.G.L. Hammond, 1992: 395-406. Queronea: Diod. 16.85, Plutarco Pelópidas 18, Alejandro 9, y Polieno Strat. 4.2.2; Moreno, ETF 25 (en prensa).

46 Jen. Anab. 3.2.19 sirve para ilustrar dicha inestabilidad: «ellos (la caballería) están suspendidos sobre los caballos y tienen miedo no sólo de nosotros, sino también de caer». Cabe recordar aquí que los caballos tampoco poseían herraduras, lo que aumenta sus posibilidades de sufrir lesiones en patas y pezuñas.

47 Véase Adcock, 1957: 50-51; Anderson, 1961: 128-30, y 1970: 58; Bosworth, 1996: 383-384; Buckler, 1990: 75-80; Cawkwell, 1978: 158-162; Cloché, 1955: 263; Hamilton, 1973: 36; Griffith y Hammond, 1979: 597-603; Hammond, 1992: 401-402; Lloyd, 1996: 189-191; Santosuosso, 1997: 120; Spence, 1993: 43-46; Tarn, 1930: 62; Wilcken, 1967: 40; Wirth, 1985: 133. Existen voces no del todo conformes (aparte de la del profesor Markle y algunos seguidores) como por ejemplo Rahe, 1981, 85: «To the best of my knowledge, no ancient historian has explained why the phalanx could withstand cavalry assault». Hutchinson, 2000: 109, sostiene una opinión ambigua, y afirma: «gradual development of cavalry deployment by a commander is seen from merely exploiting gaps in the line, to creating such gaps for exploitation». Ferrill, 1985: 177, opina que, a propósito de Queronea en 338, la caballería pudo desprenderse de sus lanzas al cargar contra la infantería, pero en cualquier caso no pone en duda dicha carga. Ellis, 1976: 197, habla igualmente de carga frontal. El ex-oficial de caballería Chenevix-Trench, 1970: 58, considera que sí podría cargarse sin estribos, pero con una silla de altos borrenes que fijase a los jinetes a la silla; véase al respecto F. Quesada Sanz, 2003: 106-7. En cualquier caso, los griegos del siglo IV tampoco conocieron dicha silla, ya que su introducción es posterior.

48 No en vano Jenofonte escribió varios tratados acerca de la monta, con las prácticas y técnicas más adecuadas, el armamento más útil, tácticas, etc. Spence, 1993, 45: «It is highly likely that the classical rider's seat was rather more secure than is usually assumed».

49 Keegan, 1976, 94-97, 153-159; Rahe, 1981: 85; Spence, 104-105. 
cosa que encontraran a su paso, al desplazarse en bloque y a la máxima velocidad ${ }^{50}$. En estas circunstancias, es fundamental la disciplina, la formación y la motivación de los jinetes, ya que la carga habría de llevarse a cabo con total cohesión, velocidad, sorpresa, ímpetu y vigor en el choque para que triunfase; el jinete debe tener un absoluto control sobre su montura, ser capaz de conducir a su caballo directamente al frente, y mantener una velocidad uniforme en la formación. Toma como referencia además al experimentado oficial de caballería del siglo XIX, L. E. Nolan, quien afirma que el elemento fundamental en la carga es el jinete, no los caballos, ya que si los jinetes no vacilan, tampoco lo harán sus monturas ${ }^{51}$.

Ciertamente, dicha teoría ofrece ciertos puntos oscuros y contradicciones. La mayoría de los grandes enfrentamientos con uso extensivo de cargas de caballería de la historia nos ha dejado constancia de ello. La caballería pesada medieval, por ejemplo, era utilizada contra la caballería enemiga y la infantería mal armada, o poco entrenada, o simples levas sin disciplina. Cargas de las que ha obtenido su reputación. Sin embargo, la mejor caballería fue derrotada frente a infantería uniformemente equipada y bien disciplinada, como leemos en Courtrai (1302), Bannockburn (1314), o las victorias de los piqueros suizos en los siglos XIV y XV. Incluso las derrotas de infantería de Hastings (1066), Conway (1295) y Falkirk (1298) nos ilustran de que, sin el estimado apoyo de los arqueros, la caballería pesada sola no garantizaba la victoria frente a infantería preparada ${ }^{52}$. Si el potencial de la caballería dependía del choque físico ¿Cómo se entiende entonces que la infantería aguantara el impacto de caballos y jinetes pesados cargando en masa? Estas batallas, y muchas otras, demuestran que la caballería no obtenía sus victorias por el choque arrollador, que es la imagen romántica y tradicional que se tiene sobre la caballería, sino por el efecto psicológico que causaban: sólo cuando se había golpeado duramente a la formación con una lluvia de proyectiles, cuando el flanco había quedado desprotegido, o cuando la infantería enemiga ha chocado ya con la propia, es entonces cuando la caballería (macedonia en este caso) tiene su posibilidad de enfrentarse a una falange con posibilidades ${ }^{53}$. Dicha posibilidad era aún mayor cuando dicha línea había perdido el orden, estaba huyendo, cuando se trataba de infantería de baja calidad, o cuando se actuaba en conjunción con la infantería.

Es en estas circunstancias en las que entra en juego el elemento psicológico: aparentemente la caballería no puede realizar una carga directa contra la infantería hoplítica en una línea perfecta, pero la simple imagen de varios centenares de caballos lanzados a la carga, golpeando el suelo con violencia, sin duda crearía una atmósfera de auténtico terror entre las filas enemigas; más aún entre aquellas que no tuvieran una moral demasiado alta, que fueran inexpertas, que hubieran sido golpeadas con anterioridad, o que directamente hubieran perdido el orden. Es en estas circunstancias en las que cualquier duda entre las filas enemigas podría deshacer la línea y la caballería, ahora sí, realizaría una auténtica matanza entre el enemigo. Es cierto que lanzar una carga sin la certeza del colapso enemigo era una baza arriesgada, ya que la caballería sin estribos y sin sillas podía caer del caballo fácilmente en la detención de la carga... demasiado cerca de las líneas enemigas. Cabe pues preguntarse hasta qué punto este elemento fue utilizado por los macedonios: pese a que con ello entramos en el peligroso terreno de la suposición, podemos suponer que Filipo y Alejandro, hábiles generales, pudieron en alguna ocasión concreta calibrar la situación y sacar provecho de algo tan fundamental como el elemento psicológico de las tropas (propias y enemigas).

50 Worley, 1994, 162-163: «Although the limitations of horses and men prevented cavalry charge from being pressed home and breaking and infantry line on many occasions, to deny that the charge was ever successful against a formed infantry is an overstatement».

51 Nolan, L. E. (1860), Cavalry: Its History and Tactics, Londres, 302: «(if) the cavalry put their horses to their utmost speed, ride home... then the (infantry) square must go down», citado por Worley, 1994: 163.

52 Oman, C. (1986): The Art of War in the Middle Ages, rev. J.H. Beeler, Nueva York 1968; H. Delbrück, vol. 3, 1975.

53 Keegan, 1976: 94-97, 153-159. 
Descartada la carga directa contra una línea estable de hoplitas, la táctica empleada por la caballería macedonia es ni más ni menos que la evolución de aquella que se estaba desarrollando en Grecia durante nuestro periodo de estudio. Aprovechando su movilidad, flexibilidad y armamento, los jinetes podían cargar directamente contra ligeros o caballería, utilizar armamento ligero para hostigar de lejos al enemigo, o aprovechar la rigidez de las formaciones de hoplitas para amenazar sus flancos, su retaguardia, o los puntos débiles que pudieran surgir en forma de huecos en la línea. Ello, unido a la apariencia intimidatoria de la caballería, podía tener un efecto devastador.

Para que dichas tácticas pudieran llevarse a cabo con garantías, la caballería macedonia debía cumplir varios requisitos: potenciar el entrenamiento y la disciplina, contar con una organización interna, una formación táctica, un armamento adecuado, tener un tamaño suficientemente elevado, así como motivación y liderazgo. Filipo se ocupó de todos y cada uno de ellos: cuenta con una amplia tradición en la monta, que remontamos en las fuentes a Amintas IV, Pérdicas III y Alejandro I54; sus jinetes reciben formación militar desde muy jóvenes; impone una dura disciplina en su ejército, privado de todo lujo; adopta la formación en cuña y la sarisa, además de la panoplia completa con que ya contaban sus jinetes; la división de la caballería en ilai, con ilarcas y mandos inferiores le confiere una mayor flexibilidad en la estructura de mando; la política de Filipo estuvo en buena parte dirigida a aumentar su tamaño, cediendo parte de las tierras conquistadas a sus jinetes, incorporando la Alta Macedonia, y aceptando en sus filas no sólo a macedonios sino también a extranjeros (tesalios, cretenses, etc.). Los resultados son bastante esclarecedores: de los 600 efectivos de que disponía en 358, pasamos a 3.000 en 353 (de la que al menos la mitad debieron ser macedonios), a 2.000 en 338 (los macedonios rondarían los dos tercios), y a 3.700 en 334 (3.300 compañeros y 400 prodromoi). En cuanto al liderazgo de ambos monarcas, creo que está fuera de duda.

Como punto fundamental en la táctica tanto de Filipo como de Alejandro, debemos referirnos a la coordinación entre las diferentes unidades del ejército macedonio, que fue lo que en realidad le dio a ambos su enorme superioridad ${ }^{55}$. Tiende a citarse Queronea como paradigma de dicha colaboración, si bien se trata de una batalla oscura que las fuentes no permiten aclarar. De acuerdo con la interpretación más común y ceñida a las fuentes, Filipo atrajo a la línea de hoplitas atenienses mediante una retirada organizada, dislocando así la línea general del ejército aliado y creando algún hueco por el que cargaría la caballería ${ }^{56}$. Buckler ofrece una teoría alternativa, a saber, que tanto Filipo a la derecha como Alejandro a la izquierda comandaron asaltos directos de infantería (falange macedonia), al considerar improbable la retirada ordenada de Polieno, y ciñéndose a Diodoro, quien no menciona la actuación de la caballería ${ }^{57}$. No obstante, no creemos que Filipo dejara de utilizar lo más valioso de su ejército, su caballería, máxime cuando contaba con un nutrido grupo.

Existen otros grandes enfrentamientos en el reinado de Filipo, más oscuros aún que el de Queronea: se trata de la batalla contra los ilirios de Bardilis de $358^{58}$, las batallas libradas contra Onomarco, en especial en la Llanura del Azafrán de $353^{59}$, y otros enfrentamientos en Olinto, Iliria y Tracia, de menor interés (en especial por la absoluta falta de fuentes). Ya he tratado de demostrar el alto peso de la caballería bajo las órdenes de Filipo en los mismos en

54 Hdt. 9.31, Tuc. 2.98.4, Diod. 15.19.3, respectivamente.

55 Moreno, ETF 15.

56 Polieno 4.2.2, 4.2.7; Diod. 16.85.5ff. y 86; Plut. Pelop. 18.7, 23.2, y Ale. 9.2 ; Hammond, 1973: 554 f.; Griffith, 1979: 596-602; Worley, 1994: 159-161.

57 Diod. 16.85.5; Buckler, 1990: 75-80; idea ya anticipada en Momigliano, 1934: 159; y Fuller (1960), 35. No obstante, se ha interpretado que unas piezas de hierro encontradas entre los restos macedonios de los caídos en batalla pertenecen a bocados de caballo, lo que estaría demostrando en buena parte la participación directa de la caballería macedonia en la batalla (Markle, 1978, 490).

58 Diod. 16.4.2-7; véase también Frontino Strat. 2.3.2.

59 Diod. 16.35.5-6; de menor importancia son Estrabón 9.5.14, y Pausanias 10.2.5. 
un artículo anterior, por lo cual baste con decir que la caballería de Filipo, como ocurrirá posteriormente con la de Alejandro, constituía el auténtico martillo del ejército macedonio ${ }^{60}$.

Todo lo dicho hasta ahora bastaría para aclarar las posibilidades tácticas de la caballería macedonia. Sin embargo, existe otro elemento que, pese a haber sido poco tratado por la historiografía contemporánea ${ }^{61}$, supone un cambio bastante substancial en el despliegue y uso de la caballería. En él, la caballería podía crear sin apoyo un hueco en la línea de hoplitas. La caballería, en formación de cuña y armada con sarisas, se dirige contra la línea enemiga sin chocar de forma violenta, combatiendo a golpe de sarisa contra los infantes, utilizando la fuerza de sus brazos y no el envite de la carga ${ }^{62}$.

En este combate es fundamental la superioridad de la sarisa sobre las lanzas hoplíticas, así como la formación apuntada que permite concentrar más el ataque. No obstante, debemos

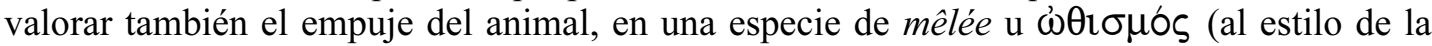
policía montada), llevada a cabo por una unidad con el tamaño suficiente (como las ilai) que podía desplazar a una línea de ocho escudos en fondo, abriendo una brecha en la línea a la par que combatía. Una vez abierto un hueco, la caballería penetra con su formación, explota hacia los lados y rebasa la línea, causando el colapso de la misma. Pero nuevamente debemos volver a los inconvenientes: la ausencia de silla de montar y estribos, el tamaño de los caballos $^{63}$, y la manejabilidad de los jinetes ${ }^{64}$ (pese al entrenamiento, en especial si consideramos que estaban armados con sarisa), reducía bastante su estabilidad, como ya vimos. La cuestión en este caso es si supuso una limitación excesiva. Es aquí donde encaja Arriano cuando dice que las unidades de caballería macedonias formadas en cuña podían cortar las formaciones enemigas ${ }^{65}$ : dicho argumento ha sido desestimado numerosas veces a la vista de lo que anteriormente comentábamos, pero en este nuevo supuesto las palabras de un oficial de caballería como Arriano cobran fuerza, pues debía conocer bien lo que era la lucha a caballo sin estribos. Por lo tanto, un jinete experimentado, que se asegurase bien sobre su montura y montando un caballo bien entrenado, podía lograr una estabilidad notable y manejar la sarisa con cierta facilidad frente a la línea de falange.

Otro punto a favor de esta teoría es la capacidad de la caballería de desplazarse con velocidad a lo largo del campo de batalla y elegir el punto sobre el que golpear. En estas circunstancias, la caballería podía buscar los huecos de que hablábamos antes, los puntos débiles, o lanzarse simplemente contra la sección previsiblemente más débil, ya que la fuerza de una cadena es igual a la de su eslabón más débil, y la rotura en un punto de una falange de hoplitas supondría el clímax de la batalla (ya que la estabilidad de un ejército hoplítico dependía en buena parte del mantenimiento de su línea regular). En este punto entra en juego también el elemento psicológico, ya que la presencia imponente y atronadora de los Compañeros se verá multiplicada en dicho eslabón. Finalmente, la escasa profundidad de la falange y la formación apuntada favorecen su rotura.

Pese a ello, consideramos que sólo en circunstancias especiales se utilizaría a la caballería de este modo.

60 Moreno, ETF 15, analiza cada uno de los grandes enfrentamientos de Filipo, haciendo hincapié en el potencial y la táctica macedonia.

61 Markle, 1977: 339, y Spence, 1994: 107.

62 Quesada, 2003a: 42, 2003b: 106-107.

63 Que pese a tener su origen en Persia o el Danubio, eran menores en tamaño a los caballos del medievo o de la actualidad, con los inconvenientes que ello conlleva. En cuanto al tipo de caballos que empleaban, se tendía a excluir a los más nerviosos, que podían romper la formación o lanzar al jinete por los aires, prefiriendo a yeguas o castrados; por otro lado, se prestaba especial atención al entrenamiento del caballo. Véase Worley, 138.

64 Conducían sus caballos apretando las piernas contra el animal para sostenerse y evitar ser desmontados, sosteniendo la brida con la mano izquierda, y la sarisa con la derecha. Véase Anderson, 1961; Vigneron, 1968; Markle, 1977.

65 Arriano, Táctica 16.6-9. 
En conclusión, el éxito macedonio tuvo su origen en la calidad y cantidad de sus jinetes, que podían asestar el golpe definitivo en el momento y el lugar precisos con una velocidad y una dureza pasmosas para la época. En estas circunstancias, la caballería dejará definitivamente de ser un mero apoyo para convertirse en el arma ofensiva por excelencia, un cambio que forma parte de la tendencia evolutiva del siglo IV a.C., y de la que Filipo es el mejor exponente. La clave, más que la sarisa, fue el nuevo papel de la caballería, paralelo y complementario al de la infantería. Eso fue lo que dio a Filipo y Alejandro la mayoría de sus victorias.

JoRge JuAn MORENO HERNÁNDEZ

Departamento de Historia Antigua, Medieval, Paleografía y Diplomática, Facultad de Filosofía y Letras, Universidad Autónoma de Madrid, Campus de Cantoblancos/n.E-mail: jorgejuan1@mi.madritel.es

\section{REFERENCIAS BIBLIOGRÁFICAS}

ADCOCK, F.E. (1957): The Greek and Macedonian Art of War, Berkeley y Los Ángeles.

ANDERSON, J.K. (1961): Ancient Greek Horsemanship, Berkeley.

Anderson, J.K. (1970): Military theory and Practice in the Age of Xenophon, Berkeley y Los Ángeles.

ANDRONIKOS, M. (1970): «Sarissa», BCH 94, 91-107.

BorZA, E.M. (1990): In the shadow of Olimpus. The emergence of Macedon, Princeton.

Bosworth, A.B. (1996): Alejandro Magno, Cambridge.

BRERETON, J.M. (1976): The Horse in War, Nueva York.

BRUN, P. (1963): «Alexander's Macedonian Cavalry», JHS 83, 27-46.

BuCKLER, J. (1980): The Theban Hegemony, Cambridge 1980.

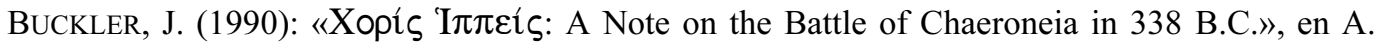
Schachter (ed.), Essays in the Topographic History and Culture of Boiotia, Montreal 1990, 75-80.

CAWKWELL, G.L. (1972): «Epameinondas and Thebes», CQ 254-278.

CAWKWELl, G.L. (1978): Philip of Macedon, Boston.

CheneVIX-TRENCH, 1970): A history of Horsemanship, Londres.

ClochÉ, P. (1955): Philippe II, Saint-Etienne.

ConNolly, P. (1981): Greece and Rome at War, Londres.

DELBRÜCK, H. (1975): History of the Art of War, vol. 1, Londres.

Devine, A. (1989): «Alexander the Great», en J. Hacket (ed.), Warfare in the Ancient World, Londres 1989, 104-128.

DuCREY, P. (1986): Warfare in Ancient Greece, Friburgo.

ELLIS, J. R. (1976): Philip II and Macedonian Imperialism, Londres.

FERRILL, A. (1985): The Origins of War, Londres.

GaUghan, P.F. (1990): The Cutting Edge: Military History of Antiquity and Early Feudal Timer, Nueva York.

GRIFFITH, G.T., y HAMMOND, N.G.L. (1979): History of Macedon, vol. 2, Oxford. 
HAMiLton, J. R. (1973): Alexander the Great, Londres.

HAMMOND, N.G.L. (1973): Studies in Greek History, Oxford.

HAMMOND, N.G.L. (1980): «Training in the use of sarissa and its effects in battle: 359-333 B.C.», Antichthon 14, 53-63.

HAMmOND, N.G.L. (1989): The Macedonian State, Oxford.

HAMMOND, N.G.L. (1990): «Royal pages, personal pages and boys trained in the Macedonian Manner during the period of the Temenid Monarchy», Historia 39, 261-289.

HAMmOND, N.G.L. (1992): «Alexander's charge in the battle of Issus in 333 B.C.», Historia 41, 395-406.

HANSON, V. (1988): «Epameinondas, the Battle of Leuktra (371 B.C.) and the Revolution in Greek Battle Tactics», ClAnt 7, 190-207.

Hutchinson, G. (2000): Xenophon and the Art of Command, Londres

KeEgan, J. (1976): The Face of Battle, Nueva York.

LAZENBY, J. (1989): «Hoplite Warfare», en J. Hacket (ed.) Warfare in the Ancient World, Nueva York, 71;

LlOYD, A.B. (1996): «Philip and Alexander the Great: the Moulding of Macedonian's Army», en A.B. Lloyd (ed.), Battle in Antiquity, Londres.

ManTI, P.A. (1983): «The Cavalry Sarissa», AncW. 8, 73-80.

MARKLE, M.M. (1977): «The Macedonian Sarissa, Spear and Related Armour», AJA 81, 323-29.

MARKLE, M.M. (1978): «Use of Sarissa by Philip and Alexander of Macedon», AJA 82, , 483-497.

Momigliano, A. (1987): Filippo il Macedone, Milan (reed. de Florencia 1934)

Moreno, J.J. «Táctica Macedonia en tiempos de Filipo II», Espacio Tiempo y Forma, Historia Antigua 15, 2004, 95-118.

PRITCHETT, W.K. (1971): The Greek State at War, Berkeley.

QUESADA, F. (2003a): «La lanza, reina de las batallas», La Aventura de la Historia, 63, 41-43.

QuesadA, F. (2003b), «Centauros Romanos», La Aventura de la Historia, 62 (2003), 106-107.

RAHE, P.A. (1980): «The military situation in Western Asia in the Eve of Cunaxa», AJP 101, 94-107.

RAHE, P.A. (1981): «The annihilation of the Sacred Band», AJA 85, 84-87.

Ste. CroiX, G.E.M. de (1972): The Origins of the Peloponessian War, Londres.

SAntosuosso, A. (1997): Soldiers, Citizens and the symbols of War, Oxford y Colorado.

SEKUNDA, N. (1992): The Ancient Greeks, Hailsham.

SNODGRASS, A.M. (1967): Arms and Armours of the Greeks, Londres.

SPENCE, I. G. (1993): The Cavalry of Classical Greece, Oxford.

TARN, W.W. (1930): Hellenistic Military and Naval Developments, Cambridge.

Vigneron, P. (1968): Le Cheval dans l'Antiquité, Nancy.

WeSTlaKe, H.D. (1975): «Xenophon and Epameinondas», GRBS 16, 23-40.

WIRTh, G. (1985): Philip II, Stuttgart.

Worley, L. (1994): Hippeis, The cavalry of Ancient Greece, Oxford. 